\title{
USO DE DATOS LIDAR PARA LA DELIMITACIÓN GEOGRÁFICA DEL RIESGO DE INCENDIO EN ZONAS DE INTERFAZ URBANO-FORESTAL (IU-F) APLICADO A GUISANDO (ÁVILA-ESPAÑA)
}

\author{
Alba María Barrado Rubio \\ Master Planificación y Gestión de Riesgos Naturales (Universidad de Alicante) \\ albabarradorrubio@hotmail.es \\ ORCID iD: https://orcid.org/0000-0001-6396-7188
}

Recibido: 18/05/2017; Aceptado: 30/04/2019.

Cómo citar este artículo/Citation: Barrado Rubio, A. M. (2019). Uso de datos LIDAR para la delimitación geográfica del riesgo de incendio en zonas de interfaz urbano-forestal (IU-F) aplicado a Guisando (Ávila-España). Estudios Geográficos, 80 (287), e014. https:// doi.org/10.3989/estgeogr.201931.011

RESUMEN: El término interfaz urbano-forestal (IU-F) es utilizado para referirse a áreas donde los espacios forestales y urbanos están en contacto, dando como resultado nuevas dinámicas territoriales, fruto del cambio de la percepción cultural del espacio que se habita.

Los incendios forestales, son un importante y creciente riesgo que hay que afrontar en estos nuevos territorios donde la gestión es más complicada y con afecciones económicas, sociales y ambientales cada vez más graves.

En este trabajo se ha llevado a cabo la delimitación de la IU-F, paso previo para llevar a cabo una adecuada gestión y prevención de los incendios forestales, tomando como referencia geográfica la población de Guisando, ubicada en el Valle del Tiétar (Ávila, España).

Los resultados demuestran como la utilización de datos LIDAR, mediante el uso de Sistemas de Información Geográfica (SIG) de software libre y código abierto, tienen un gran potencial, y son válidos para delimitar y gestionar espacios de riesgo.

PALABRAS CLAVE: Interfaz urbano-forestal; incendios forestales; datos LIDAR; SIG; software libre; código abierto.

\section{LIDAR DATA USE FOR THE GEOGRAPHICAL DELIMITATION OF FIRE RISK IN WILDLAND-URBAN INTERFACE (WUI) APPLIED TO GUISANDO (ÁVILA, SPAIN)}

ABSTRACT: The term Wildland-Urban interface (WUI) is used in order to refer to areas where forest and urban spaces are combined, resulting in new territorial dynamics, due to the changes of the cultural perception of the space which is inhabited.

Forest fires are an important and growing risk to be faced in these new territories, where the management is more difficult, which generates socioeconomic and environmental repercussions.

In this work the delimitation of Wildland-Urban interface has been developed. It is the first step to create a suitable management and prevention of forest fires. All this process was carried out using a geographical reference Guisando, located in the Tietar Valley (Ávila, Spain).

The results show the prospective of the uses of LIDAR data, through the Geographic Information System (GIS) technologies with free and open source software. Moreover, they are valid to manage and delimit spaces at risk.

KEY WORDS: Wildland-Urban interface; Wildfire; LIDAR data, GIS, free software, opensource. 


\section{INTRODUCCIÓN}

La Interfaz Urbano-Forestal (IU-F) hace referencia a territorios donde entran en contacto espacios forestales y urbanos. Son nuevos paisajes fruto de una nueva concepción de los espacios naturales y su idealización. Como manifiesta Vince et al. (2005), esta definición aparentemente simple lleva consigo una realidad compleja, donde los subsistemas social/urbano y natural/forestal tienen gran cantidad de interacciones e intercambios. Donde hay que tener en cuenta de manera simultánea, tal y como señala Badia et al. (2015), varios factores: establecer una frontera clara entre espacios urbanos y forestales, una legislación ambigua y a una población con cada vez menos percepción del riesgo de incendio.

De esta forma, junto la protección de las masas forestales, en estos espacios se suma la protección de las edificaciones e infraestructuras, así como la de vidas humanas, lo que dificulta enormemente la priorización y toma de decisiones a la hora de abordar un incendio.

En los últimos años la utilización de los SIG y datos georreferenciados viene siendo común para la gestión de los incendios forestales en sus distintas facetas: prevención, planificación, seguimiento, extinción... dado su gran potencial para visualizar y analizar de manera conjunta distintas facetas de la realidad territorial (vegetación, topografía, demografía, usos del suelo...). En el ámbito español el Dr. Chuvieco se presenta como pionero y son numerosas sus aportaciones sobre el tratamiento de los incendios forestales a través de SIG.

Lo cierto es que actualmente ya es bastante común la utilización de estas herramientas para gestionar los incendios forestales a nivel administrativo ya que «resulta cada vez más evidente la importancia de contar con mejores herramientas para el conocimiento y gestión de los incendios. El empleo de las tecnologías de información geográfica proporciona nuevas posibilidades de obtener y gestionar información espacial, de cara a mejorar nuestra toma de decisiones sobre el territorio» (Chuvieco et al., 2007, p.19).

Evidenciado el riesgo y las ventajas de la utilización de SIG, queda de manifiesto la necesidad de delimitar correctamente estas zonas como paso previo a una gestión adecuada. Por eso este trabajo se configura como un estudio cartográfico preliminar y necesario, pues la correcta identificación de estas zonas derivará en una mejor gestión.
El objetivo de este estudio ha sido establecer una metodología sencilla y flexible para establecer el fenómeno a gran escala, utilizando como fuente de datos principal los datos LIDAR complementados con otras fuentes de información como el Mapa Forestal Español (MFE). Con esta información se ha planteado un enfoque para delimitar las zonas y jerarquizarlas en función del riesgo. Para ello se han utilizado SIGs de acceso libre y código abierto.

Resaltar que iniciativas como las de la fundación OSGEO $^{1}$ han permitido demostrar con tiempo y esfuerzo que los proyectos basados en open source geográfico pueden ser de tanta calidad y competitividad o más que los que se desarrollan con software comercial. Según Richard M. Stallman, conocido como el fundador del Movimiento del Software Libre por su publicación del manifiesto GNU (Linux), el concepto del software libre se basa en:

- Libertad para ejecutar el programa con cualquier propósito.

- Libertad para estudiar cómo funciona y adaptarlo a las necesidades del usuario.

- Libertad para distribuir copias y compartirlas con otros usuarios.

- Libertad para mejorarlo y compartir dichas mejoras con otros usuarios con el objetivo de que también puedan beneficiarse del programa.

Este tipo de programas abiertos suelen ser gratuitos, pero no se debe asociar software libre con software gratuito, lo importante es que se trata de una cuestión de libertad de uso y manipulación, no de precio.

Por todo esto este estudio pretende poner de manifiesto la validez y ventajas de estos sistemas para detectar el riesgo de incendio de las edificaciones que se encuentran en IU-F; destacando la precisión en la obtención, tratamiento y procesamiento de la información con datos LIDAR y la agilización en las salidas de campo que se obtiene, ya que muchas veces cubrir todo el terreno de una forma exhaustiva no es factible ni fácil.

Situación actual de la IU-F a diferentes escalas espaciales

\section{Ámbito europeo}

En los últimos años la Comisión Europea ha comenzado a financiar distintos proyectos de investigación para estudiar el fenómeno de la IU-F. Proyectos como WARM $^{2}$ o FIRESTAR ${ }^{3}$ son los más representativos. 
Pero, aunque es un problema bien consolidado, todavía no existe una normativa sobre IU-F que los estados miembros deban transponer a su legislación, lo que hace que un análisis a escala europea sea complicado de realizar. Modugno et al. (2016) realizó una cartografía para todo el ámbito europeo, utilizando variables estadísticas que expresan el valor de la probabilidad de que un incendio forestal afecte a zonas residenciales visualizadas en un rango de 0 a 1 . El resultado de este estudio pone de manifiesto el riesgo de los países mediterráneos, la periferia de las grandes ciudades europeas, así como el riesgo potencial de algunas áreas industriales de Rumanía o Albania; y destaca la necesidad de realizar una política conjunta.

\section{Ámbito estatal}

En España, la IU-F tiene especial renombre en la costa mediterránea, así como en las coronas metropolitanas de las grandes ciudades, pero lo cierto es que su peso es cada vez mayor y aunque se conozca la problemática «se conoce poco sobre la magnitud superficial del fenómeno y su distribución espacial» (Galiana, 2012, p. 209).

Actualmente el Ministerio de Agricultura y Pesca, Alimentación y Medio Ambiente (MAPA) tiene publicado el "Estudio básico para la protección contra incendios forestales en la Interfaz Urbano Forestal" realizado por la empresa Tecnoma (2010), donde se exponen los diferentes tipos de IU-F en España y su peso en cada provincia. Aparece IU-F en zonas de matorral, zonas agroforestales e incluso zonas adehesadas, gran diversidad de espacios de riesgo que dificulta su localización y consecuente gestión.

\section{Ámbito autonómico}

La normativa estatal ha incorporado el concepto de IU-F en su ley de Montes de 2003, pero son las Comunidades Autónomas (CCAA) las que tienen el deber de legislar sobre ellas. A pesar de ello tan solo algunas de ellas lo han hecho; Cataluña es pionera en el tema con su Ley 5/2003, de 22 de abril; Madrid (Plan INFOMA), Valencia (Guía Metodológica de Actuaciones de Prevención, Defensa y Autoprotección) o Extremadura (Plan Peifex); el resto tan solo recoge alusiones indirectas en otras normativas, siendo común «la obligación de ejecutar franjas de seguridad de anchura variable para reducir la intensidad del incendio» (Galiana, 2012, p. 219).

Castilla y León que tras Galicia es la segunda comunidad con mayor incidencia de incendios forestales, tiene desarrollada abundante legislación sobre ellos. Cabe destacar el Plan INFOCAL donde además de disponer cómo deben abordarse estos eventos, hace un análisis municipal sobre el riesgo, la vulnerabilidad y el peligro de incendio, pero aun así sigue sin disponer de un respaldo legislativo sobre IU-F.

\section{Ámbito comarcal y municipal}

En lo referente al municipio de Guisando y a la Comarca del Valle del Tiétar a la cual pertenece, no existe ningún plan o acción concreta para la IU-F. Tan solo algunas acciones $u$ ordenanzas concretas para evitar incendios forestales, y en muchos casos previamente emitidas por organismos administrativos superiores, como, por ejemplo, la Junta de Castilla y León. La regulación de las quemas o el uso de barbacoas son algunos ejemplos.

El estudio de Abad Soria et al (2007), resalta las características naturales y sociales por la que se configura como una zona de riesgo y pone de manifiesto la necesidad de realizar legislación y gestión consecuente en toda la comarca, no habiéndose desarrollado ningún estudio más detallado posteriormente tanto a nivel comarcal como municipal.

\section{Metodología y fUENTES}

\section{Zona de estudio}

El municipio de Guisando (Figura 1), con una población en torno a los 500 habitantes pertenece a la Comarca del Valle de Tiétar. Situada en la vertiente sur de la sierra de Gredos en la provincia de Ávila.

Es una zona rural de montaña con predominio de zonas de cultivo y bosques, a los que se suma una topografía abrupta, con pendientes acusadas, todo ello en la vertiente de solana de un sistema montañoso como es la sierra de Gredos, en el que además los incendios forestales son recurrentes en los meses estivales.

\section{Metodología}

Para realizar el estudio se estructuró de la siguiente manera. Una vez definido el objeto que se quería abordar se comenzó empleando visores cartográficos, en específico se utilizaron el PNOA ${ }^{4}$ y SIGPAC 5 para buscar y seleccionar posibles zonas de riesgo. Una vez seleccionadas se procedió a su visita a través de una salida de campo para comprobar in-situ el riesgo, de esta forma se fueron desechando las que se consideraba que no cumplían los requisitos y se aña- 
FIGURA 1

LOCALIZACIÓN ZONA DE ESTUDIO
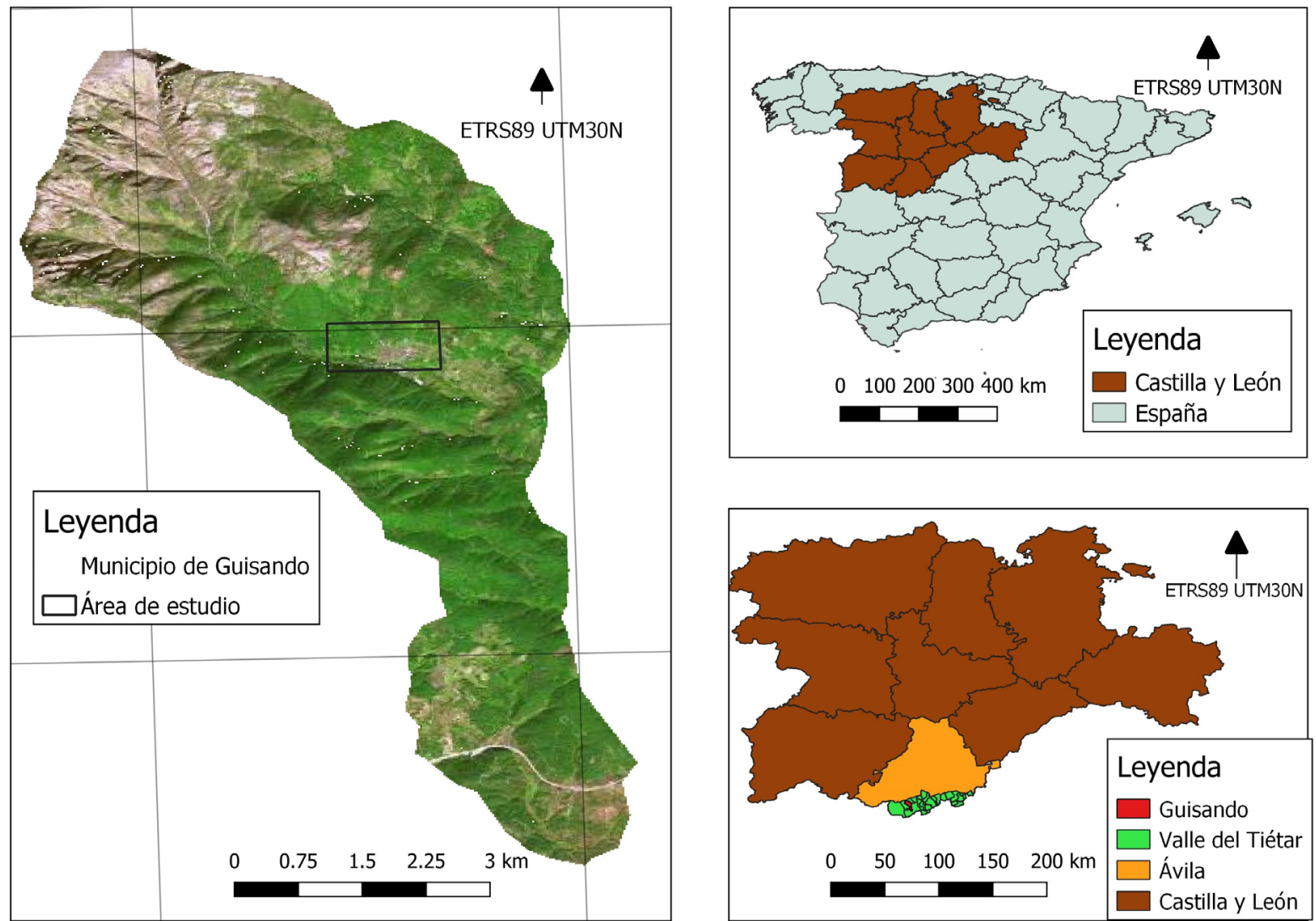

Fuente: Elaboración propia con los límites administrativos del IGN y el PNOA

dieron otras zonas que no habían sido detectadas previamente. Finalmente, todas las zonas de riesgo fueron digitalizadas.

En este punto es importante destacar que el presente artículo nace del Trabajo Fin de Máster "Delimitación de la Interfaz Urbano-Forestal (IU-F) y riesgo de incendio con Tecnologías de Información Geográfica" ${ }^{\prime \prime}$ (Barrado, 2016) en él se plantean tres ejemplos a distintas escalas para delimitar la IU-F, utilizando en cada una de ellas fuentes distintas (satelitales para pequeñas escalas, Infraestructuras de Datos Espaciales de España para medias escalas y datos LIDAR para grandes escalas).Tras la salida de campo y la ejecución del estudio a medias escalas se confirmó que la población de Guisando tenía peligrosidad por lo que se seleccionó para llevar a cabo el trabajo con datos LIDAR, estos datos LIDAR serían acompañados por la información del MFE para abordar la información referida a la vegetación.
Una vez seleccionada la zona de estudio se concretó un esquema especificando todos los pasos a desarrollar para geoprocesar la información, todo ello siempre con la utilización de software libre y preferiblemente de código abierto (QGIS, SAGA, GRASS, LasTools).

\section{Fuentes}

\section{Mapa Forestal Español (MFE) ${ }^{6}$}

La Ley 43/2003, de 21 de noviembre, modificada por la Ley $26 / 2010$, de 28 de abril determina en su artículo 28 las bases por las que debe regirse el Mapa Forestal, su metodología y la periodicidad (al menos decenal) con la que debe renovarse. Se establece, así como la cartografía forestal oficial de España, donde se representa la ubicación de las diferentes masas forestales.

Su elaboración pasa por diferentes etapas: fotointerpretación de imágenes digitales (en su mayoría 
procedentes del proyecto OLISTAT ${ }^{7}$, pero también de ortofotos e imágenes satélite propias de cada Comunidad Autónoma) que finaliza en una digitalización tanto de las formaciones artificiales como naturales existentes. Derivada de esta digitalización, se lleva a cabo una salida de campo para visitar todas las teselas que den lugar a dudas (aproximadamente un 75\% de las teselas visitadas) y un pequeño porcentaje (aproximadamente el 25\%) de visitas de comprobación. El último paso es un control de calidad de régimen interno, aunque de manera opcional se puede, además, realizar un control externo. La provincia de Ávila y con ello la zona de estudio de este trabajo, cuenta con ambos controles.

Presenta un modelo de datos jerarquizados, distinguiendo entre los principales usos del suelo y las clases forestales existentes, tomando como referencia principalmente las especies arbóreas. Tales características le permiten ser muy útil para diferentes ámbitos de actuación como la ordenación del territorio, así como para el objeto de estudio del presente trabajo, pues supone una fuente de datos estandarizada para todo el territorio que se renueva con periodicidad y que aporta un elemento de información imprescindible para trabajar con la IU-F como es la vegetación.

\section{Datos LIDAR}

Light Detection and Ranging o datos LIDAR son el resultado de una técnica de teledetección que utiliza la luz de un láser para obtener información con gran precisión de la superficie de la tierra $(x, y, z)$. Este láser, ya sea aéreo transportado (con aviones o helicópteros) o mediante plataformas terrestres debe disponer de GPS e INS (sistema de navegación inercial) en el caso de los aéreotransportados, para medir la rotación, inclinación y encabezamiento del sistema LIDAR.

El reflejo de los rayos láser emitidos hacía la superficie son recogidos por los receptores del sensor que determinan el tiempo que tardan en llegar desde que son emitidos para calcular la distancia, junto con la información del GPS y del INS, dando lugar a una nube de puntos (puntos tridimensionales) que representan la realidad tanto del terreno como de los elementos que contiene, ya que en función de los rebotes del láser se puede extraer dicha información y ver elementos superpuestos que con otras técnicas más tradicionales como la fotogrametría es imposible. Hay que diferenciar entre LIDAR topográfico y LIDAR batimétrico (penetra en el agua).
A día de hoy los datos LIDAR se están configurando como una gran fuente de información que permite con gran precisión y cantidad de datos estudiar la superficie terrestre y sus formaciones tanto naturales como antrópicas, a la vez que disminuye los costes y tiempos de realización.

Los datos LIDAR correspondientes se descargaron de la Infraestructura de Datos Espaciales (IDE) de Castilla y León ${ }^{8}$, en concreto el producto 0578 página 1-3, de la que se realizó un recorte que abarca principalmente el núcleo de población de Guisando y sus inmediaciones.

\section{Métodos}

\section{Trabajo de campo}

La justificación de la elección de la zona de trabajo viene dada por varias razones, por una parte, el conocimiento previo de la Comarca del Valle del Tiétar y su problemática con los incendios forestales. Por otra parte, estudios a medias y pequeñas escalas puede favorecer la concreción de las áreas de estudio de detalle con datos LIDAR, como se demuestra en el Trabajo Fin de Máster "Delimitación de la Interfaz Urbano-Forestal (IUF) y riesgo de incendio con Tecnologías de Información Geográfica" del que se ha extraído el presente artículo.

El procedimiento comenzó con una visualización a través del WMS del PNOA de la zona de estudio. El núcleo de población no presentaba grandes urbanizaciones dispersas en las inmediaciones como otros pueblos del valle, pero el mismo pueblo se encuentra muy cercano a las masas forestales. Posteriormente la salida de campo (Figura 2) confirmó totalmente la peligrosidad de su ubicación por lo que selecciona como ejemplo para desarrollar el estudio.

\section{Análisis mediante uso de datos LIDAR}

Previamente al tratamiento de los datos LIDAR con programas SIG se utilizó el programa ejecutable LasTools que permite trabajar con la nube de puntos en formato LAS de una manera rápida y sencilla. Los formatos LAS oficiales ya vienen con una clasificación previa oficial de los puntos que fue definida por la Sociedad Americana de Fotogrametría (ASPRS)..$^{9}$ En base a esta clasificación de los puntos se seleccionaron, en la proyección correspondiente (UTM30N) los puntos asociados a datos de suelo (clasificación 2), vegetación de baja, media y alta (clasificación 3,4, y 5, respectivamente), y por último la referida a urbano (clasificación 6) que han sido pasados a formato texto para poder utilizarlas en otras herramientas de SIG. 
FIGURA 2

FOTOGRAFÍAS ZONA DE ESTUDIO, GUISANDO
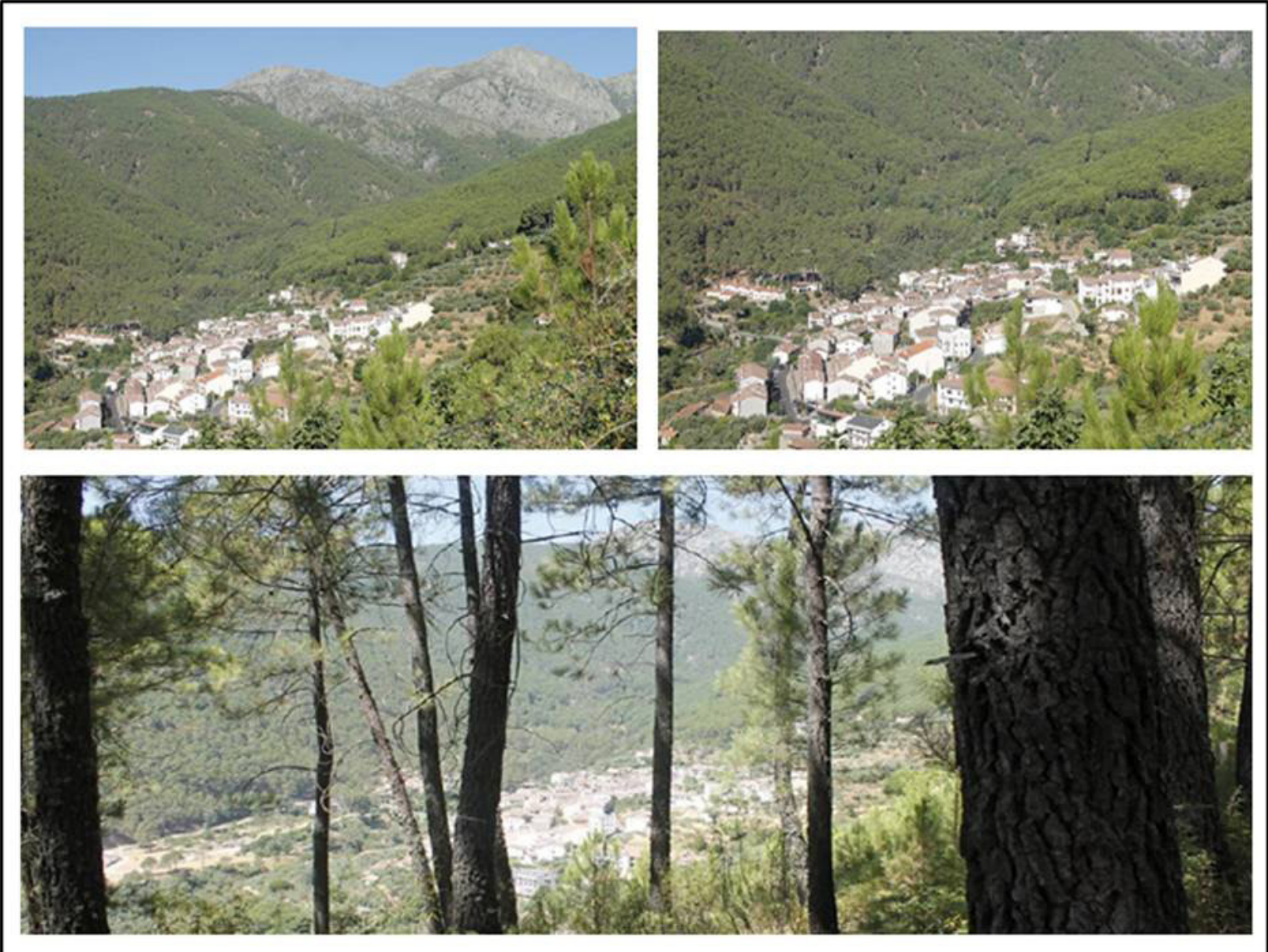

La información LIDAR se convirtió en shape a través del formato texto resultante de LasTools y se generó un MDT con los datos del suelo. Por último, se utilizó la información del Mapa Forestal de España, para así poder detectar y comprobar los principales usos del suelo y formaciones de vegetación. Todas estas capas fueron recortadas con la zona de estudio escogida y son las entradas que se muestran en el esquema de geoproceso (Figura 3).

La metodología utilizada sigue los pasos empleados en el "Estudio básico para la protección contra incendios en la interfaz urbano-forestal", anteriormente mencionado. En ella se tiene en cuenta tanto la situación de las viviendas respecto a las masas forestales como la topografía circundante. Para la primera premisa se establecieron las siguientes distancias:

- Hasta 10 metros (influencia por radiación-convección), las llamas más fuertes pueden llegar hasta las viviendas.
- Hasta 30 metros: bajo influencia de las pavesas de corto recorrido.

- Hasta 100 metros: bajo la influencia de las pavesas de largo recorrido.

Seleccionando los puntos correspondientes a vegetación alta, media y baja se crearon tres capas diferenciadas, aplicando un buffer de distancia de 100, 30 y 10 metros respectivamente. De manera paralela a la capa de puntos urbanos se le aplicó un buffer de distancia de un metro para crear polígonos aproximados de la realidad. Tras la realización de estos dos pasos ya fue posible hacer una visualización conjunta detectando que edificaciones quedan en zonas de riesgo.

Para establecer la gradación de riesgo se analizó la topografía en base a las pendientes y las orientaciones derivadas del MDT, que ha sido creado a través de los puntos LIDAR de suelo con una resolución de pixel de 3 metros. Para ello se utilizó el método 
FIGURA 3

ESQUEMA DE GEOPROCESO

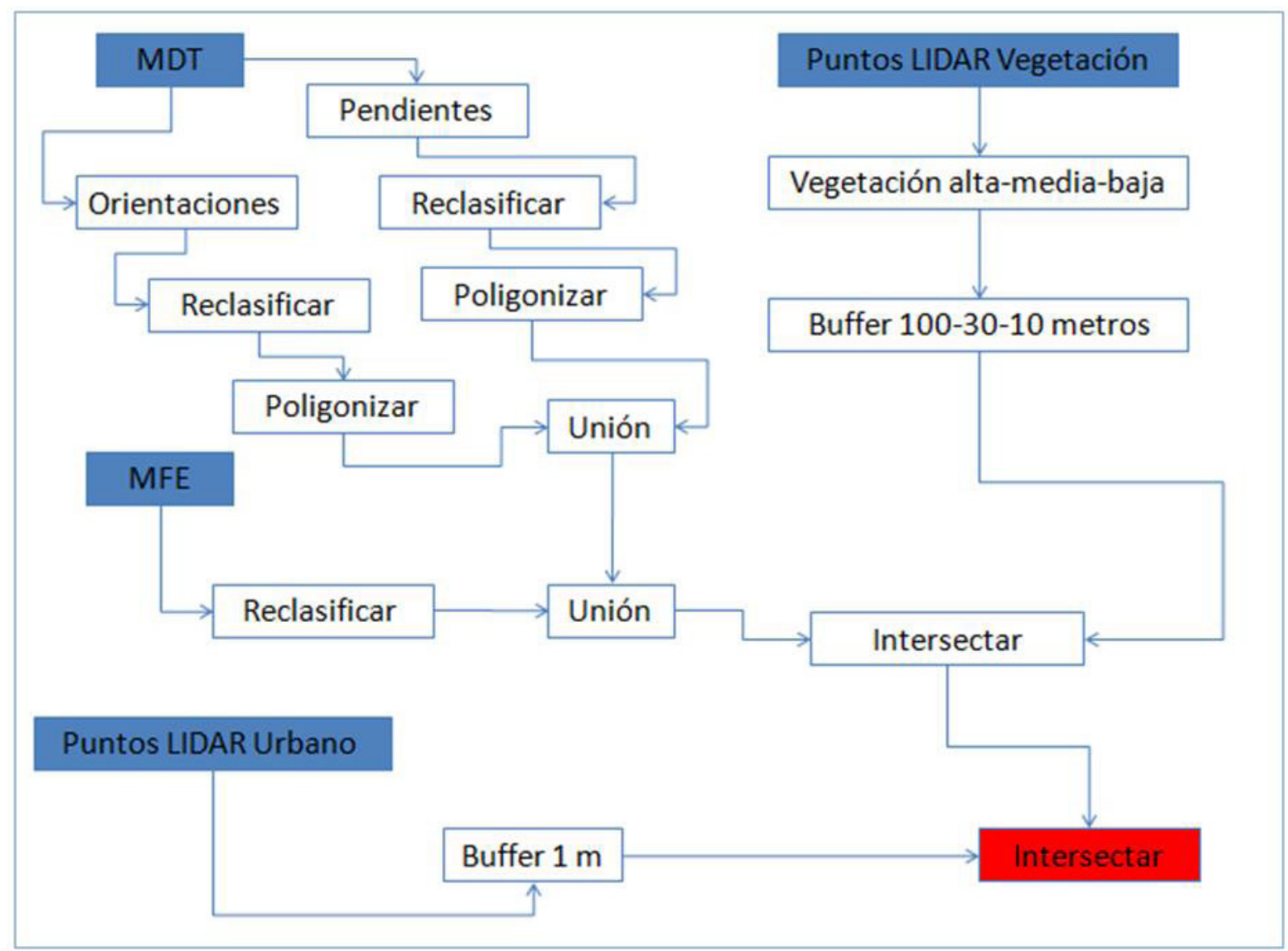

Las capas de entrada están representadas por el color azul, el color rojo representa la capa final, y en blanco se representan todos los procesos realizados a partir de la capa de entrada hasta que se llega a la capa final.

Fuente: Elaboración propia

HORN, método global que suaviza la imagen resultante (Horn y Schunck, 1981).

Una vez sacadas las orientaciones y pendientes se reclasificaron en niveles de peligrosidad y se vectorizaron para poder geoprocesarlas con el resto de información.

La pendiente "favorece la propagación por transmisión de calor (radiación, convección) y continuidad vertical del combustible" (Hernando et al, 2014, p. 21). En la reclasificación se estimaron como riesgo alto las pendientes superiores a 15 , y como bajo riesgo las que estaban por debajo de ese valor.

Las orientaciones inciden de varias maneras, las vertientes orientadas a la solana (sur) tendrán más riesgo de sufrir un incendio ya que hay un menor grado de humedad en el ambiente, y un mayor estrés hídrico en la vegetación, comparada con las situadas en la umbría (norte). Otros factores como la dominancia de los vientos también vienen determinados por la orientación. En el caso del Valle del Tiétar los vientos que más repercusión tienen son los provenientes del sur y suroeste, ya que rebotan en la sierra y permanecen más tiempo en el valle, mientras que los provenientes del norte chocan con la vertiente norte de Gredos, evitando su incidencia en el valle. Por estas razones se consideraron como zonas de riesgo alto para la reclasificación, las zonas entre 135-315‥

La intersección de las dos variables se clasificó de la siguiente manera: riesgo bajo donde coincidían riesgo bajo tanto en orientaciones como en pendientes; riesgo medio donde una de las dos variables tenía riesgo 
alto y la otra, bajo; y riesgo alto donde ambas variables tenían riesgo alto, es decir, pendientes $>15$ 으 con orientaciones entre 135-315ㅇ.

Una vez detectadas las zonas de más riesgo en base a la topografía, se procedió a analizar la información del MFE sobre usos del suelo y tipos de vegetación. Esta información fue reclasificada y unida a la capa de riesgo topográfico.

Obtenidas las zonas de riesgo se realizó una intersección con las áreas de influencia establecidas (100, 30 y 10 m) de vegetación.

Finalmente, el último paso fue una intersección de las zonas de riesgo con los elementos urbanos, lo que permio obtener los diferentes grados de riesgo de las edificaciones urbanas de Guisando en función del riesgo por convención-radiación, pavesas de corto recorrido o pavesas de largo recorrido.

\section{RESULTADOS Y DISCUSIÓN}

El análisis de Guisando, población que se encuentra en IU-F, ha detectado zonas de riesgo alto y muy alto en casas y edificios públicos, los cuales en su mayoría se encuentran en los bordes del núcleo o cercanos a él, colindando o ya inmersos en los pinares.

En la Figura 4 se muestra como todas las infraestructuras urbanas quedan bajo la influencia del buffer de 30 $\mathrm{m}$, así como una buena parte lo hace del buffer de $10 \mathrm{~m}$. El buffer de $100 \mathrm{~m}$ no fue representado ya que ocupaba toda el área de estudio quedando todas las infraestructuras afectadas. Es importante señalar la detección de la vegetación ornamental o pequeños jardines dentro del núcleo de población que puede aumentar y magnificar los resultados del SIG. El hecho de mantener los parques limpios tiene gran importancia pues puede evitar o disminuir el riesgo ante un incendio.

FIGURA 4

ELEMENTOS URBANOS EN LAS ÁREAS DE INFLUENCIA DE 10 Y 30 METROS
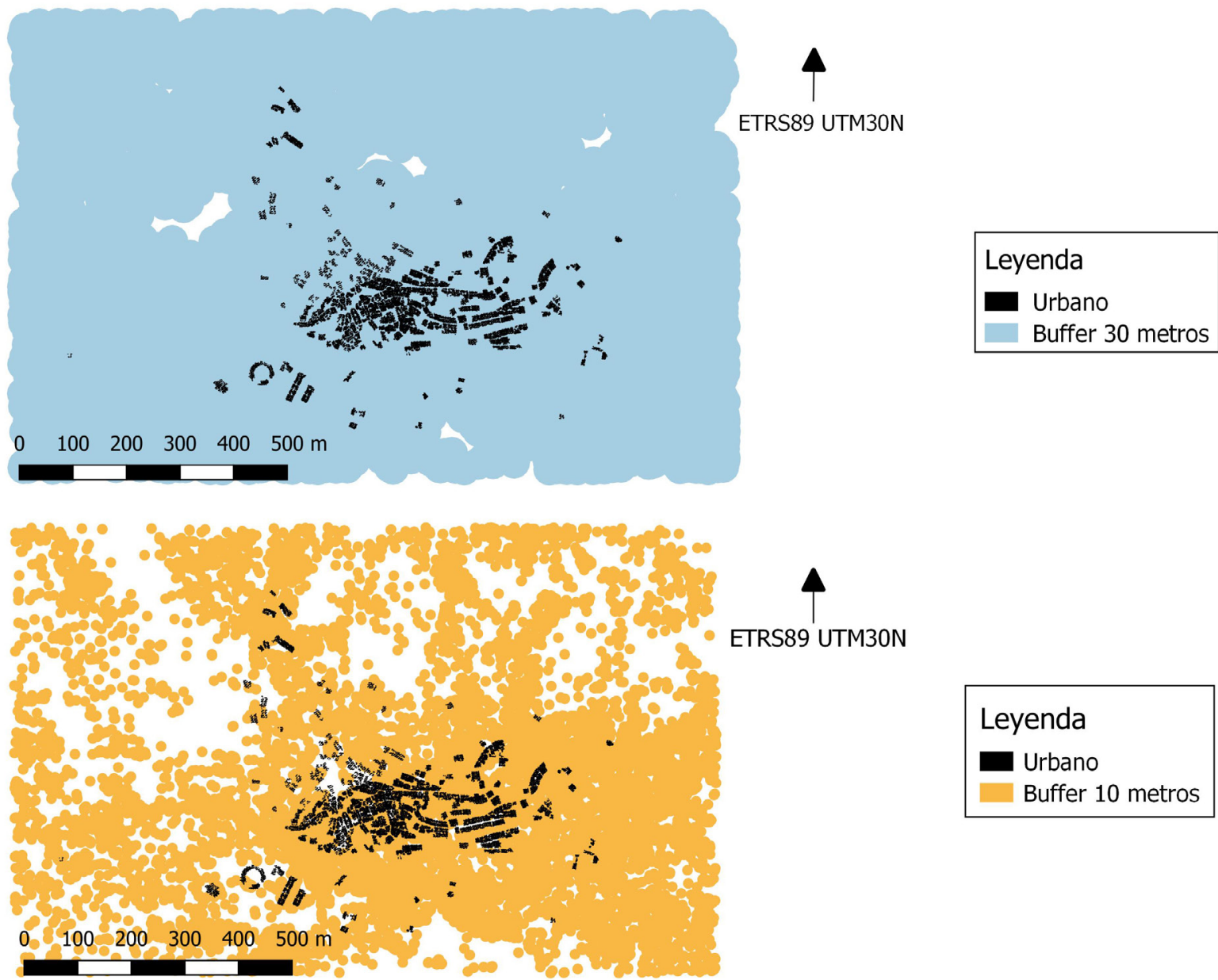

Fuente: Elaboración propia. 
En cuanto al riesgo topográfico, como se muestra en la Figura 5, también un importante porcentaje de las viviendas se sitúan en zonas de riesgo alto. Destacar que la mayoría de las líneas con riesgo bajo o medio que aparecen se corresponden con carreteras y caminos, que ante un incendio de poca potencia pueden actuar como cortafuegos, pero ante incendios grandes pueden suponer un taponamiento de las vías de escape.

Atendiendo a la clasificación de los usos del suelo, como se muestra en la Figura 6, las zonas arboladas según la clasificación del MFE, corresponden en su totalidad a "Pinares de pinus pinaster en región mediterránea", no obstante, durante el trabajo de campo se pudo comprobar cómo existen mezclados entre los pinares algunos robles y castaños. Las zonas de cultivo, situadas al sur y este de la población, son mayormente olivares y, en menor medida, cerezos; este tipo de arbolado medio, aunque serviría para ralentizar un pequeño incendio, también puede facilitarlo si el in- cendio es muy virulento, sobre todo si estos cultivos se encuentran en estado de abandono. Para la reclasificación se tomó los pinares como zonas de alto riesgo, a los cultivos como zonas de riesgo medio y la zona artificial como riesgo bajo.

La unión de las capas de topografía y usos del suelo (Figura 7) permitió realizar una gradación del riesgo a través de la suma de los valores de las diferentes reclasificaciones. Se puede observar como el pueblo se encuentra rodeado de zonas con riesgo alto, y situado principalmente en zona de riesgo medio.

Al intersectar la información con los buffer, se obtuvieron para cada área de influencia el riesgo existente. Como se ha comentado anteriormente, la intersección con el buffer de 100 y 30 m es innecesaria ya que abarcan todas las infraestructuras por lo que es resultado es el mismo que representa la Figura 7. Sí fue necesario intersectar el buffer de $10 \mathrm{~m}$, como se muestra en la Figura 8.

\section{Intersección pendientes y orientaciones}

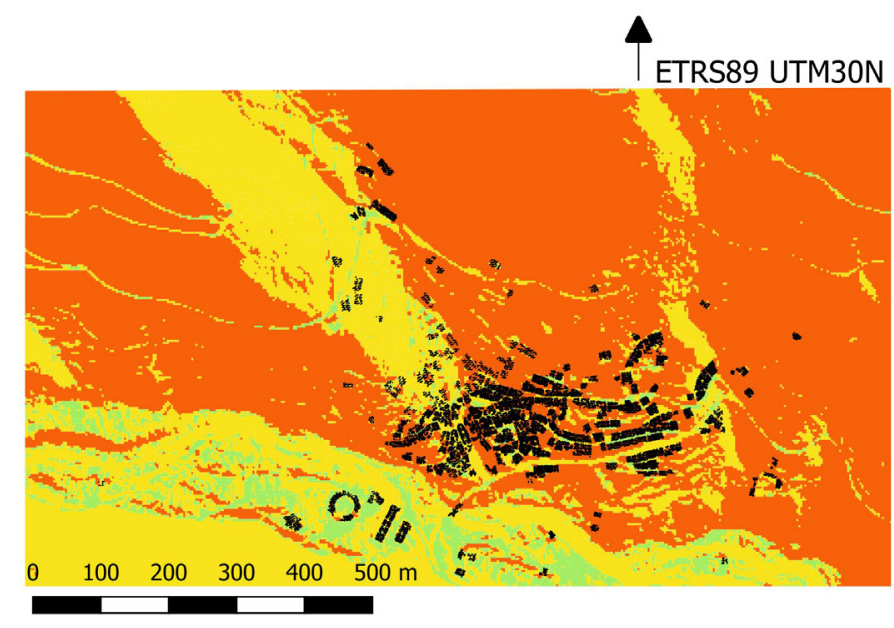

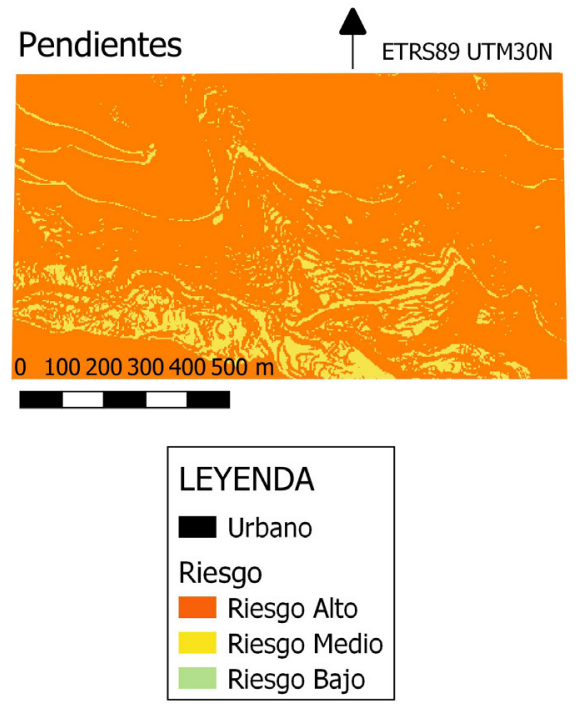

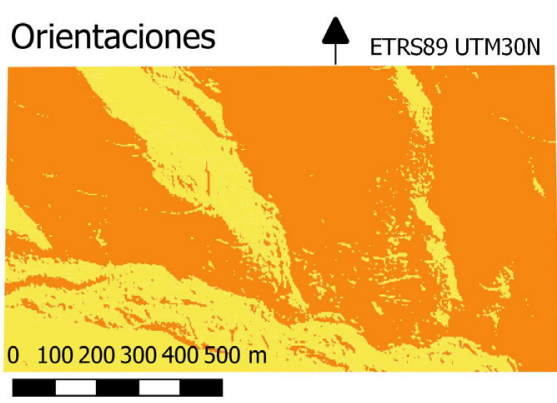

Fuente: Elaboración propia. 
FIGURA 6

CLASIFICACIÓN DE LOS USOS DEL SUELO

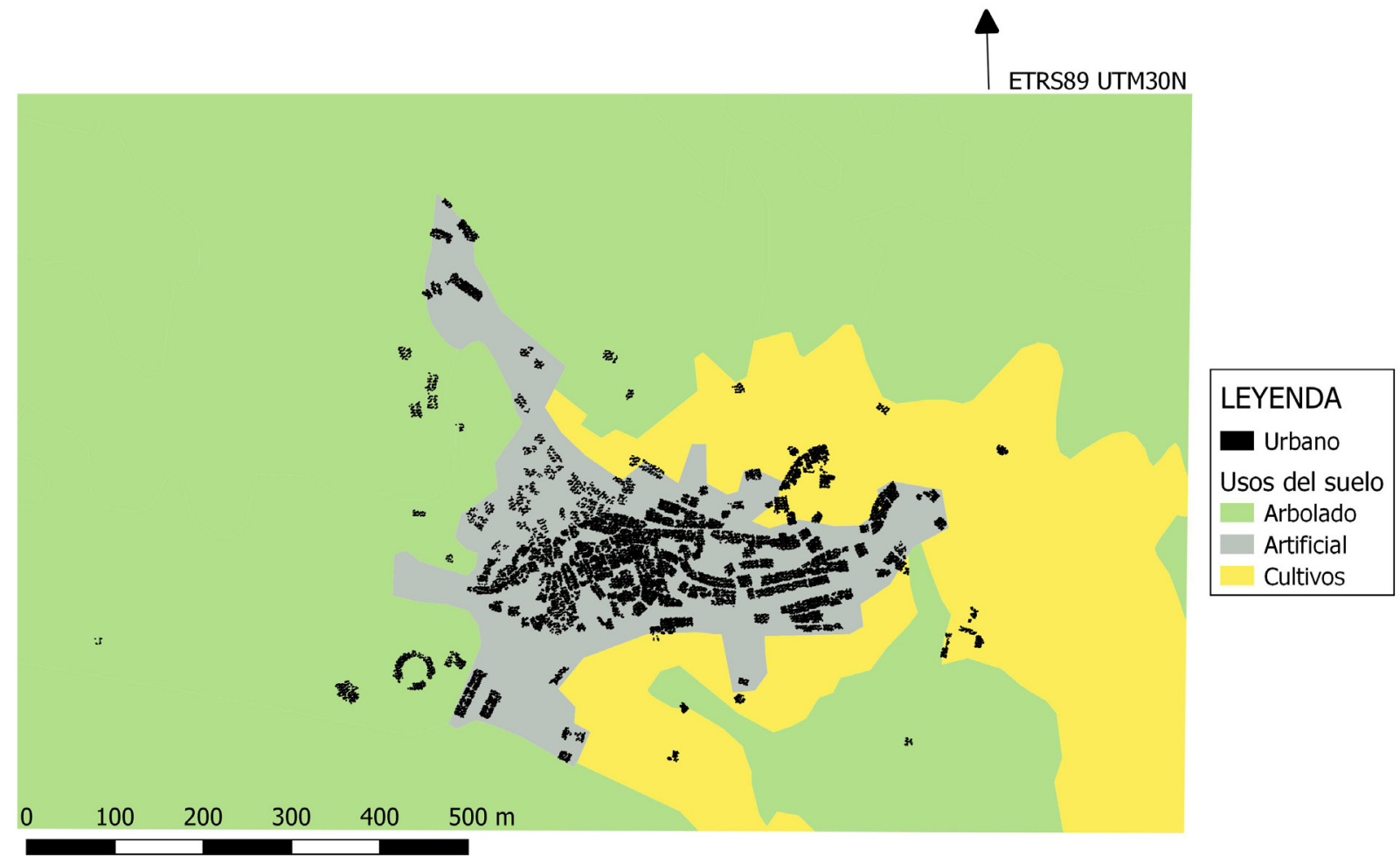

Fuente: Elaboración propia, con datos del MFE.

FIGURA 7

RIESGO SEGÚN LA TOPOGRAFÍA Y USOS DEL SUELO

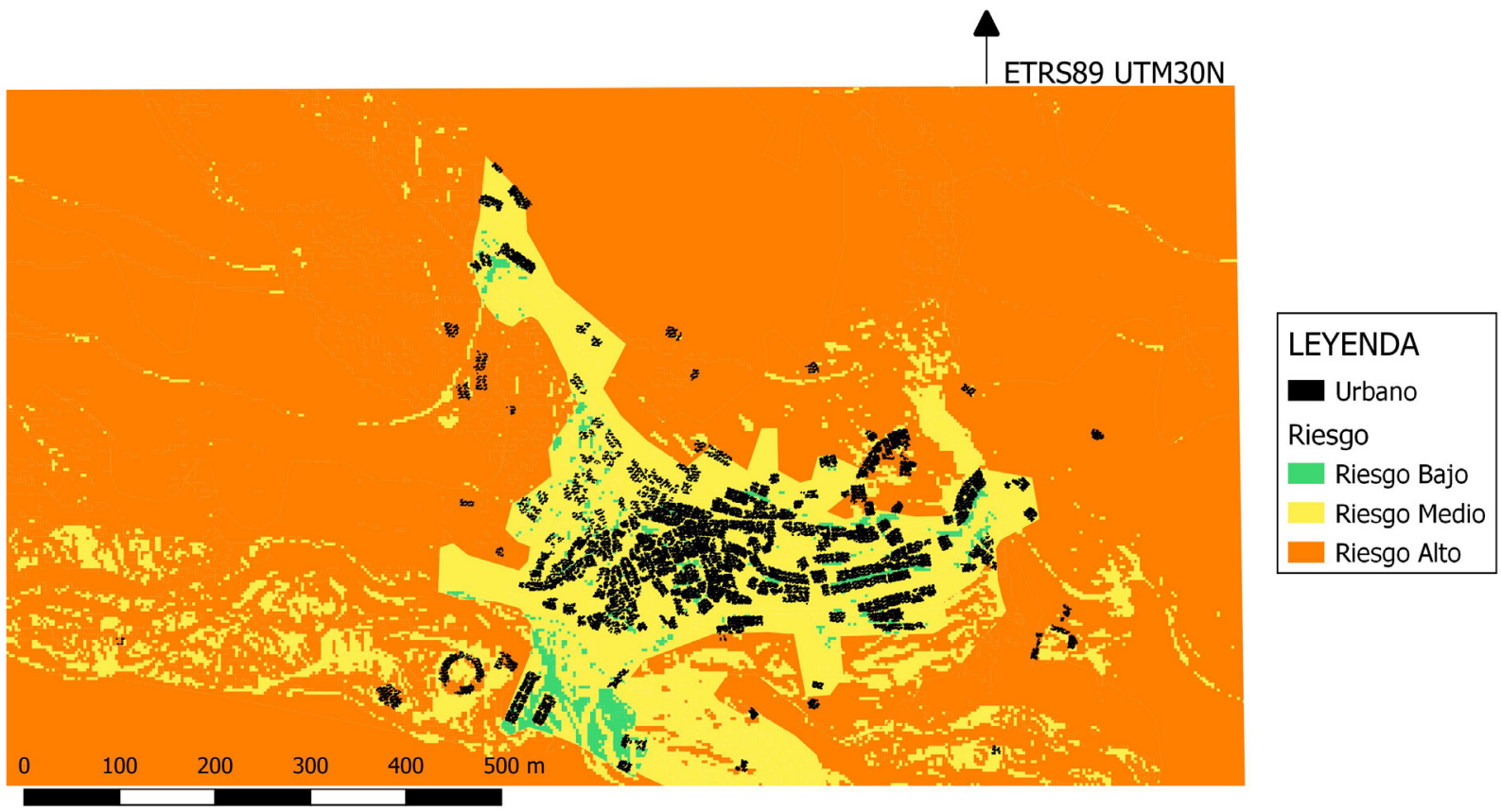

Fuente: Elaboración propia. 


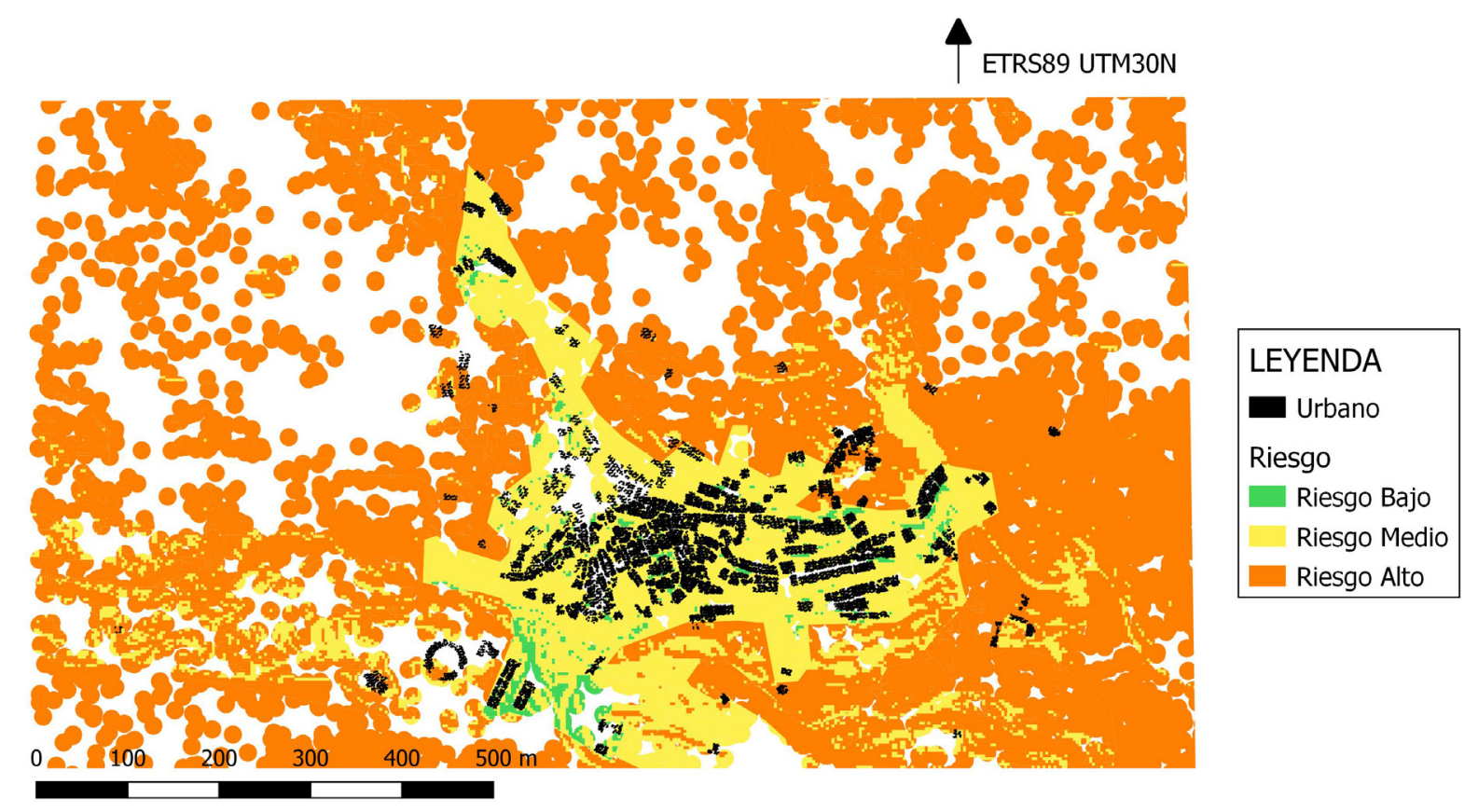

Fuente: Elaboración propia.

Finalmente, en la Figura 9 se muestra la gradación del riesgo atendiendo ya solo a las infraestructuras, que en la mayoría de los casos se encuentran influenciadas por los tres buffers. En general la mayoría de la población se encuentra en riesgo medio, siendo las infraestructuras de borde de población las que presentan riesgo alto.

Una vez obtenidos todos estos resultados, destacar igualmente la necesidad de evaluar otros aspectos como los materiales constructivos, a los cuales se les podría atribuir una gradación del riesgo para analizarlos con el resto de criterios evaluados en este estudio. Además, es importante conocer otros aspectos como la percepción de la población hacia los incendios forestales y el entorno donde residen, así como las medidas que desde la administración o propias de los mismos habitantes se llevan a cabo para prevenir y actuar ante los incendios forestales, lo que ayudará a llevar una gestión más controlada, pudiendo implantar medidas estructurales, pero también no estructurales, contribuyendo al aumento del conocimiento y de la concienciación de la población.

En cuanto a la vegetación, ya existe bibliografía e iniciativas respecto a la utilización del LIDAR para establecer inventarios forestales o modelos de combusti- ble forestal. A día de hoy la cartografía de los modelos de combustible «deriva del mapa forestal de España y no tiene unas buenas propiedades en lo que se refiere a nivel de detalle y frecuencia de actualización por ello que se intente encontrar una forma de mejorar esta cartografía» (Chavero, 2011, p. 6). Debido al potencial de los datos LIDAR se puede obtener información tanto de la cantidad de combustible existente como su distribución espacial, mejorando notablemente la resolución, el tiempo y los costes de la cartografía actual. Todo esto llevaría a una mejora a la hora de predecir cómo podría comportarse un incendio forestal en caso de producirse.

En el ámbito español destacar los estudios realizados por Marino et al. (2016a; 2016b), para el ámbito de las Islas Canarias, o en La Rioja con el grupo Forest-LidaRioja ${ }^{10}$ que desarrollan inventarios forestales y mapas de modelos de combustible con tecnologías LIDAR.

De esta forma y con un conocimiento más exhaustivo del tema de la vegetación el presente estudio se podría realizar enteramente con datos LIDAR, sin necesidad de utilizar el MFE. Recordar que nos encontramos ante una comarca donde apenas existen estudios (a excepción del estudio de Abab Soria) a pesar de que queda evidenciado el riesgo que sufre. 


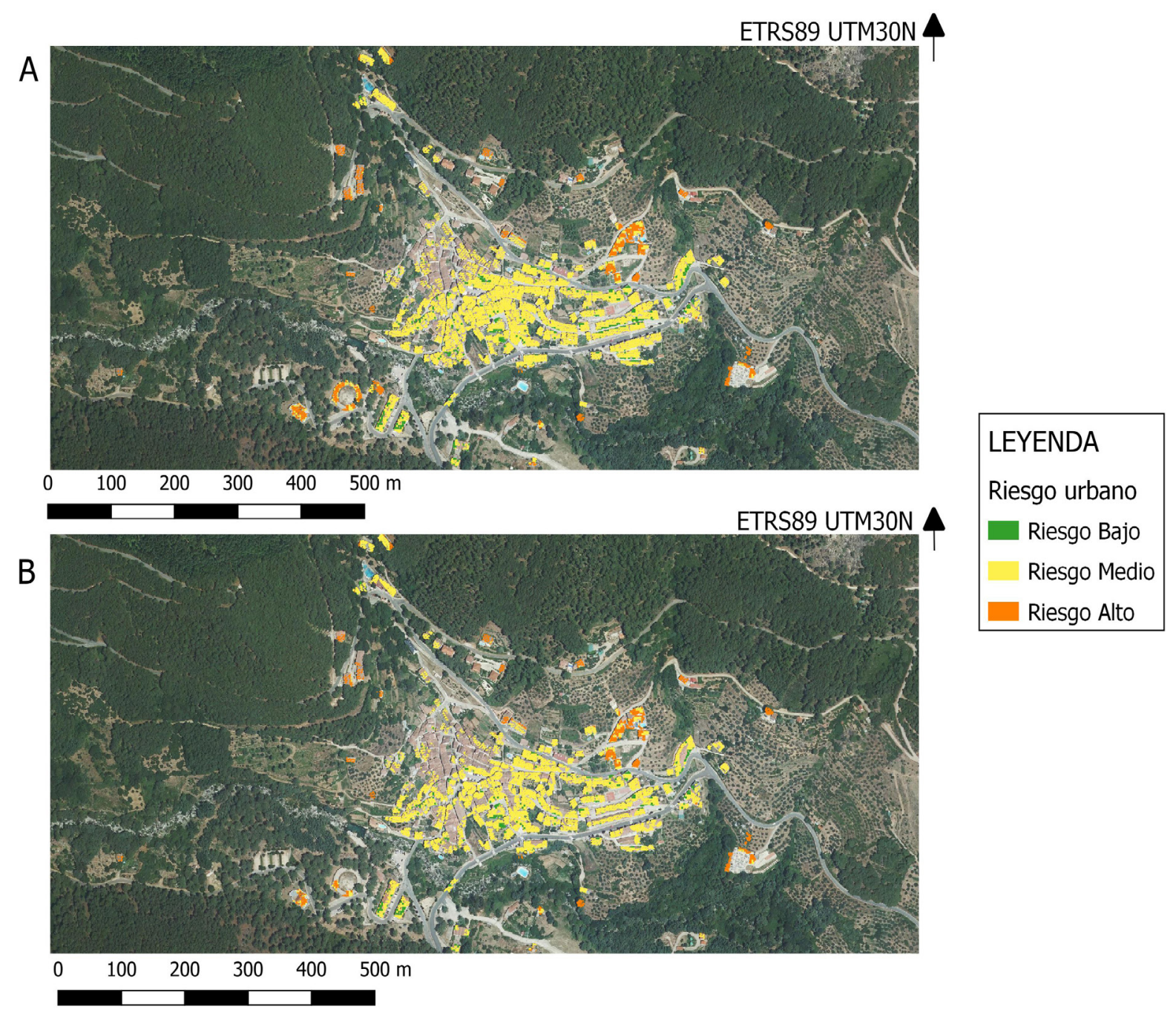

Fuente: Elaboración propia.

Finalmente, en cuanto al manejo de datos LIDAR, los resultados ponen de manifiesto que pueden ser de gran utilidad para delimitar IU-F, ya que aportan gran cantidad de información del terreno y con un mínimo manejo y análisis pueden generar información derivada de interés. Igualmente destacar algunos inconvenientes, la descarga de la página 1:25.000 contenía más de 650 millones de puntos, lo que hace que se necesite un hardware muy potente para tratar la información, agudizándose el problema a escalas de menos detalle. Otro problema encontrado es que los datos LIDAR pueden contener errores. En el presente trabajo aparecían zonas urbanas inexistentes en plenos escarpes de la sierra o dentro del núcleo había edificaciones que no aparecían representadas.

\section{CONCLUSIONES}

Actualmente la información geográfica se configura como una herramienta de trabajo de gran utilización para la gestión de los riesgos naturales, y en concreto para la delimitación de IU-F, objeto de estudio del presente estudio. La utilización de programas SIG de carácter libre y abierto, además, permite delimitar las IU-F a un bajo coste, teniendo en cuenta la situación actual. Este trabajo pone de manifiesto cómo es posible realizar la delimitación cartográfica del fenómeno a través de este tipo de herramientas y con uso de datos LIDAR, realizando además una gradación del riesgo en función de las características naturales del terreno y los usos del suelo. 
Los datos LIDAR se consolidan como una gran fuente de datos que permiten un análisis del terreno en profundidad, detectando situaciones que se pueden escapar en el trabajo de campo y en las visualizaciones de ortofotos (falta de capacidad de trabajo, problemas de accesibilidad o visibilidad...), ayudando a poder definir zonas en las que vale la pena procesar una información muy voluminosa y costosa de manejar.

Como inconveniente el trabajo con datos LIDAR en equipos y programas SIG convencionales a escalas medias o pequeñas, supone dificultades debido a la cantidad de información a procesar. De igual manera, los fallos hallados (zonas urbanas no detectadas, o

\section{NOTAS}

1. https://www.osgeo.org/

2. WARM: https://cordis.europa.eu/project/rcn/59893/ factsheet/en

3. Firestar: http://www.eufirestar.org/es_proyecto.php

4. PNOA: https://pnoa.ign.es/

5. SIGPAC: http://sigpac.mapa.es/fega/visor/

6. MFE: https://www.miteco.gob.es/es/cartografia$\mathrm{y}$-sig/ide/descargas/biodiversidad/mfe.aspx

\section{BibLIOGRAFÍA}

Abad Soria, J., García Quiroga, F., y Cepeda Serna, C. (2007). La situación de los incendios en el Valle del Tiétar. Observatorio Medioambiental, 10, 123-143. Recuperado de https://revistas. ucm.es/index.php/OBMD/article/view/OBMD0707110123A/21359

Badia, A., y Valldeperas, N. (2015). El valor histórico y estético del paisaje: claves para entender la vulnerabilidad de la interfaz urbano-forestal frente a los incendios. Scripta Nova. Revista Electrónica de Geografía y Ciencias Sociales, 19. https://doi. org/10.1344/sn2015.19.15125

Barrado Rubio, A.M., (2016). Delimitación de la Interfaz Urbano-Forestal (IU-F) y riesgo de incendio con Tecnologías de Información Geográfica (TIG) (Trabajo de Fin de Máster). Universidad de Alicante. Recuperado de http://rua.ua.es/dspace/handle/10045/58496 puntos urbanos que no lo son), manifiesta que, aunque son un extraordinario complemento en la delimitación cartográfica, su uso debe ir acompañado de trabajo de campo previo y posterior al proceso SIG, evitando generar errores importantes y por lo tanto una gestión incorrecta.

Finalmente, destacar la utilización del WEB 2.0 que permite divulgar, compartir y elaborar información de forma colaborativa en Internet. Los SIG permiten la publicación de los datos de las IDEs o de los estudios relativos al fenómeno en geoportales colaborativos, es decir, GeoWikis o mapas colaborativos en que los habitantes o entidades interesadas pueden contribuir a enriquecer la información y mejorar su divulgación.

7. Proyecto OLISTAT: proyecto financiado por la Comisión Europea cuyo objetivo era determinar el número de olivos existentes en los países de la Comunidad Europea, para ello se realizó un vuelo fotogramétrico en 1997/1998.

8. Datos LIDAR: https://cartografia.jcyl.es/web/jcyl/ Cartografia/es/Plantilla100/1284417641842/__

9. ASPRS: https://www.asprs.org/

10. Forest-LidaRioja: https://www.forest-lidarioja. info/noticias/

Chavero Melgar, P. (2011). Cartografía de modelos de combustible del monte № 117 del C.U.P. (Término municipal de Cuenca) basada en datos de sensores remotos (Trabajo de Fin de Grado). Universidad Politécnica de Madrid. Recuperado de http:// oa.upm.es/6573/2/PFC_PABLO_CHAVERO_MELGAR.pdf

Chuvieco, E., Aguado, I., Yebra, M., Nieto, H., Martín, M.P., Vilar, L., Martínez, J., Padrón, D., Martín, S., Salas, J., (2007). Generación de un Modelo de Peligro de Incendios Forestales mediante Teledetección y SIG. En Teledetección. Hacia un mejor entendimiento de la dinámica global y regional (pp. 19-26). Mar de Plata: Editorial Martin.

Galiana Martín, L. (2012). Las Interfaces Urbano-Forestales: Un nuevo territorio de riesgo en España. Boletín de la Asociación de Geógrafos Españoles, 58(5), 205-226. 
Hernando, C. Guijarro, M., Díez, C., San Martín, J., Madrigal, J., (2014). Laboratorio de incendios forestales Cifor-nia. España: Ministerio de Ciencia y Tecnología.

Horn, B.K.P., Schunck, B.G. (1981). Determining optical flow. Artificial Intelligence, 17(1-3), 185-202.

Marino, E., Ranz, P., Tomé, J.L., y Noriega, M.A., (2016a). Cartografía de alta resolución de modelos de combustible forestal: metodología de bajo coste basada en datos LIDAR. FORESTA, 65, 34-42.

Marino, E., Ranz, P., Tomé, J.L., Noriega, M.A., Esteban, J., Madrigal, J. (2016b). Generation of highresolution fuel model maps from discrete air borne laser scanner and Landsat-8 OLI: a low-cost and highly up dated methodology for large areas. Remote Sensing of Environment, 187, 267-280. https://doi.org/10.1016/j.rse.2016.10.020

Modugno, S., Balzter, H., Cole, B., Borrelli, P., (2016). Mapping regional patterns of large forest fires in Wildland-Urban Interface areas in Europe. Journal of Environmental Management, 172, 112-126.

Tecnoma Grupo TYPSA (2010). Estudio básico para la protección contra incendios forestales en la interfaz urbano-forestal. MAPA.

Vince, S.W., Duryea, M.L., Macie, E.A., Hermansen, A. (eds.) (2005). Forests at the wildland-urban interface: conservation and management. Boca Raton: CRC Press. 